\title{
Metodologias ativas em um curso de formação em saúde
}

\section{Methodologies active in a training course in health}

\author{
José de Ribamar Ross", Aurilivia Carolinne Lima Barros², Jainara Gomes da Silva ${ }^{3}$, Jociel \\ Ferreira Costa 4 , Natália Pereira Marineli ${ }^{5}$, Joseane da Costa Ximenes Rocha ${ }^{6}$ \\ 1 Professor Assistente do Departamento de Ciências da Saúde da Universidade Estadual do Maranhão - Campos Caxias. Mestre em \\ Enfermagem pela Universidade Vale do Rio dos Sinos - UNISINOS. Doutorando em Ciências da Saúde pela Faculdade de Ciências Médicas da \\ Saúde da Santa Casa de Misericórdia de São Paulo-FCMSCSP Brasil.E-mail: enfross@hotmail.com \\ 2Mestranda em Enfermagem pela Universidade Federal do Pará. Belém-PA Brasil.E-mail: aurilivia.barros@gmail.com \\ ${ }_{3}^{3}$ Mestre em Saúde da Família. Coordenação de enfermagem da Faculdade do Vale do Itapecuru. E-mail: jainaragdaniel@hotmail.com \\ ${ }^{4}$ Licenciado em Ciências com habilitação em Biologia. Mestre em Ciência Animal - UFPA. Doutorando do Programa de Pós-graduação em \\ Ciência Animal pela Universidade Estadual do Maranhão. Núcleo de Estudos Morfofisiológicos Avançados - NEMO. São Luís-MA Brasil. E- \\ mail: jocielfcosta@gmail.com \\ ${ }^{5}$ Doutoranda em Tecnologia e Sociedade pela Universidade Tecnológica Federal do Paraná-UTFPR. Professora do Colégio Técnico de Teresina \\ da Universidade Federal do Piauí. Teresina-PI Brasil. E-mail: nataliamarinelli@ufpi.edu.br *Autor para correspondência \\ ${ }^{6}$ Mestre em Saúde da Família no Ciclo Vital. Clínica Dr. Flávio Rocha LTDA. Teresina-PI Brasil. E-mail: ximenesjoseane3@gmail.com.
}

\author{
Palavras-chave \\ Educação permanente \\ Ensino \\ Metodologias ativas
}

\section{Keywords}

Education continuing

Teaching

Active methodologies

\begin{abstract}
O objetivo é conhecer as reflexões de um especializando sobre o uso das metodologias ativas no curso anteriormente citado. Trata-se de um estudo de abordagem construtivista da educação de adultos, traduzida numa combinação de metodologias ativas de ensino-aprendizagem, colaborativa e compromissada com as necessidades da sociedade, na busca de aprofundar, de modo crítico e reflexivo, o conhecimento cientificamente produzido nas áreas de gestão, saúde e educação. Dentre as metodologias ativas utilizadas destacou-se o espiral construtivista, a metodologia problematizadora, a aprendizagem baseada em equipes entre outras ações educacionais diversificadas e eficientes.
\end{abstract}

The objective is to know the reflections of a specialist on the use of active methodologies in the aforementioned course. It is a study of constructivist approach to adult education, translated into a combination of active teaching-learning methodologies, collaborative and committed to the needs of society, in the search to deepen, in a critical and reflective way, the scientifically produced knowledge in management, health and education areas. Among the active methodologies used, the constructivist spiral, the problematizing methodology, teambased learning, among other diversified and efficient educational actions, stood out.

\section{INTRODUÇÃO}

O Curso de Especialização em Gestão de Políticas de Saúde Informadas por Evidências é resultado de uma parceria entre o Ministério da Saúde - MS e o Hospital Sírio-Libanês - HSL, por intermédio do Instituto Sírio-Libanês de Ensino e Pesquisa - IEP/HSL, e faz parte do projeto do HSL de Apoio ao Sistema Único de Saúde, que integra o Programa de Apoio ao Desenvolvimento Institucional do Sistema Único de Saúde. Um dos diferenciais das propostas educacionais do IEP/HSL é a utilização de uma abordagem construtivista da educação de adultos, traduzida numa combinação de metodologias ativas de ensino-aprendizagem. Por meio da perspectiva, os cursos de especialização buscam estimular a capacidade de aprender a aprender, o trabalho em equipe, a postura ética, colaborativa e compromissada com as necessidades da sociedade, além de aprofundar, de modo crítico e reflexivo, o conhecimento cientificamente produzido nas áreas de gestão, saúde e educação (SILVA, 2015).

O profissional de Saúde deve possuir competências para a qualificação do processo decisório em saúde e está direcionado a formuladores de políticas e tomadores de decisão de alto e médio comando dos governos municipal, estadual e federal, gestores de sistemas locais de saúde, apoiadores da gestão de saúde, pesquisadores interessados na temática e membros do controle social da saúde (CHIARELLA et al., 2015).

Um dos principais desafios das políticas de saúde é promover o uso sistemático de evidências científicas na sua formulação e implementação e no país esse desafio é ainda mais significativo, onde os resultados das políticas de saúde são condicionados também por fatores socioeconômicos e os recursos disponíveis são limitados. Nesse cenário, o uso das melhores evidências científicas disponíveis deve ser 
empregue com o objetivo de melhorar a aplicação de recursos, buscando mais efetividade na promoção, prevenção e atenção à saúde (BRASIL, 2016).

Assim a utilização de uma abordagem construtivista da educação de adultos, traduzida numa combinação de metodologias ativas de ensino-aprendizagem busca estimular a capacidade de aprender a aprender, o trabalho em equipe, a postura ética, colaborativa e compromissada com as necessidades da sociedade, além de aprofundar, de modo crítico e reflexivo, o conhecimento cientificamente produzido nas áreas de gestão, saúde e educação (FOFONCA et al., 2018).

Nessa perspectiva o presente relato tem com o objetivo demostrar as reflexões de um egresso na perspectiva da formação em gestão de políticas de saúde informadas por evidências tendo como subsídios das metodologias ativas.

\section{MATERIAL E MÉTODOS}

Trata-se de um estudo descritivo desenvolvido através de um relato de experiência acerca do curso de Gestão de Políticas Públicas Informadas por Evidências- GPPIE. Fundamentado nos pressupostos teóricos pedagógicos de Vigotski que preconiza o educando como um sujeito elaborador de seu próprio conhecimento, onde este educando é fortemente influenciado por aspectos sociais e culturais.

Uma das principais teoria de Vygotsky é a zona de desenvolvimento proximal (ZDP) que caracteriza-se pela existência de 3 status de aluno. Assim existe o aluno expertise que já alcança os objetivos de forma independente. $O$ aluno aprendiz que só aprende com assistência de um facilitador e o aluno novato que não aprende nem com a assistência de um facilitador. Deste modo o professor necessita reconhecer e alinhar-se com todos os diferentes tipos de alunos desde o ponto de partida rumo ao norte na perspectiva de uma trajetória ruma a aprendizagem de qualidade (FREITAS, 2001)

Com base nas análises de conteúdo dos registros do portfólio construtivo produzidos durante o curso permitiram as descrições aqui narradas. Para efeitos didáticos este relato será apresentado em três fases distantes representando os movimentos de uma viagem rumo às metodologias ativas subsidiadas por uma interlocução com o referencial bibliográfico e pressupostos teóricos da pedagogia progressista que favoreceram a epistemologia do processo de ensino aprendizagem.

Assim o sujeito que elabora o conhecimento, transforma seu meio e conduz este processo por meio de sua ação e reflexão. O ser humano e o seu meio não se sobrepõem, mas interagem estas relações transformam-se mutuamente.
(THOFEHRM; LEOPARDI, 2006).

Utilizou-se o método de análise de conteúdo de Laurence Bardin, pois por essa técnica possibilitar uma maior organização do estudo. Trata-se de um grupo de procedimentos de averiguações das narrativas, que utiliza ações sistematizadas das descrições do conteúdo das falas. A proposta da análise de conteúdo é a dedução de conhecimentos relacionados às situações de produção (ou ocasionalmente, de recepção), indução esta que recorre a indícios (subjetivos ou não) (MOZATO, 2011).

No primeiro momento ou etapa definida como pré-análise o pesquisador organiza o estudo através de leituras e buscas de matérias sobre o tema para o desenvolvimento do então estudo, criando suas hipóteses, objetivos e os indicadores que darão base e credibilidade ao tema proposto na pesquisa (CAREGNATO; MUTTI, 2006).

Já na etapa seguinte os dados obtidos e todos os materiais e falas passam a ser codificadas pelas unidades de registro e já na terceira etapa que é o momento de analisar e interpretar os dados o autor do estudo irá transcrever as falas registradas categorizando-as por suas semelhanças dentro de cada item que serão discutidas levando em consideração cada questão padronizada pelo questionário utilizado.

Conforme Resolução Conselho Nacional de Saúde № 466, DE 12 de dezembro de 2012 o trabalho não foi submetido a provação em comitê de ética em pesquisa com seres humanos tendo em vista se tratar de um relato de experiência. Num momento de discussão dos efeitos da tecnologia da informação e da revolução da inteligência artificial já presentes na educação 4.0 este trabalho traz na esteira desta provocação a discussão das práticas mobilizadoras de modo que o docente possa refletir sobre suas práticas educativas de forma livre para assim questionar seus efeitos, vantagens e desvantagens para criar e inovar através do seu conhecimento as diferentes metodologias ativas narradas.

\section{RESULTADOS E DISCUSSÃO}

\section{Movimento I: A decolagem}

$\mathrm{Na}$ chegada ao curso as competências a serem almejadas foram: Formar competências para alicerçar a produção de pesquisas enquanto pesquisador que atua na academia e na estratégia de saúde da família; Qualificar a produção científica produzida enquanto pesquisador; Ter contato com novas práticas pedagógicas construtivistas e inovadoras para utilização no cotidiano de trabalho; Participar de um processo de formação em saúde pelo Instituto de Educação Permanente do Hospital Sírio Libanês.

As competências apresentadas no caderno do curso e, a 
serem alcançadas são: Na gestão de políticas públicas de saúde: Analisar contextos na gestão das políticas públicas de saúde; Identificar prioridades na gestão de políticas públicas de saúde; Tomar decisão em saúde utilizando evidências científicas; Avaliar a tomada de decisão informada por evidências. Na atenção à saúde as competências são: promover a atenção à saúde informadas por evidências. $\mathrm{Na}$ educação em saúde as competências são: construção do conhecimento para a ação política: Identificar necessidades de aprendizagem no uso de evidências científicas; Apoiar o uso de evidências científicas; Apoiar a produção de novos conhecimentos em políticas de saúde informadas por evidências (SILVA, 2017).

Enquanto aluno e/ou professor durante a jornada de vida percebemos o conceito de competências como algo a ser gerado no educando ao final de um processo educativo tendo uma relação direta a partir dos conteúdos apreendidos nas estratégias de ensino aprendizagem, o que equivaleria aos objetivos a serem alcançados e necessários para o alcance das habilidades e atitudes.

A competência pode ser conceituada como a qualidade de movimentar, interpor e propor uma atividade em prol do saber, fazer, e dos valores essenciais envolvidos para uma ação com eficiência e efetividade exigidas no ambiente do trabalho. (DELUIZ, 2001; EPSTEIN; HUNDERT, 2002). O que corrobora nosso entendimento, pois a competência gerada traduz na competência daquilo que se assimila e faz uso habitual e detalhado dos saberes, processos de comunicação, o fazer técnico, o pensamento clínico, faz uso de valores, costumes, sentimentos e percepções no cotidiano do serviço de saúde onde atua ou na comunidade.

Ao término do curso percebeu-se que a estratégia de ensino de construção do portfólio contribuiu fortemente para a formação da competência, que é analisar contextos na gestão das políticas públicas de saúde e a identificar prioridades desta enquanto que, a competência de tomar decisão em saúde utilizando as evidências científicas e a sua avaliação para implementação e tomada de decisão foi alicerçada pelas oficinas de trabalho que teve como objeto os diversos contextos das evidências científicas, referências bibliográficas e as buscas de evidencias científicas em repositórios. Todas as atividades e aulas tinham como foco a busca de evidências científicas e, os exercícios e atividades provocadas como as sínteses provisórias e permanentes nos deixou clara esta filosofia de trabalho a ser seguida. A compreensão foi ampliada quanto ao uso das evidencias indo além do campo meramente acadêmico para um campo altamente prático dando sentido a gestão de políticas públicas nunca antes vislumbrando.

Estes movimentos permitiram compreender a necessidade de levar estes conhecimentos e técnicas do campo teórico e ao cotidiano de trabalho como fonte de eficiência para transformar nossos processos de trabalho. Somente foram possíveis através das metodologias ativas que tornou tudo mais fácil e agradável de entendimento. Deste modo houve uma ampliação de visão daquilo que imaginávamos que iria alcançar com o que foi realmente postulado e alcançado pelas competências proposta do curso. A compreensão e as competências propostas foram todas fomentadas e alcançadas. Muitas estratégias e conteúdos vistos foram inovadores nos eixos das metodologias ativas e, esta experiência será levada em conta pois percebemos a gestão dos serviços de saúde pública precisando ser transformada e as dicas apreendidas serão muito bem utilizadas como estratégia.

A gestão dos serviços de saúde em boa parte é conduzida de forma pragmática pelos gestores onde, o planejamento é fragmentado e sem foco para os problemas reais e intervenções descontextualizadas e sem evidências. Aprendemos que o planejamento é a base de tudo e deve ser recheado de informações e indicadores de saúde para conduzir as buscas de evidencias científicas para propor opções e implantações de barreiras.

\section{Movimento II: O percurso da viagem}

\section{Processo Ensino Aprendizagem}

Com o passar dos dias, fomos observando o contexto apresentado e as expectativas do percurso vislumbrados, onde fomos inundados por sentimento de apreensão e encanto. O curso também vinha em um momento em que estávamos experimentando outras experiências dentro do campo de atuação profissional em que estávamos inseridos.

Nas leituras preliminares do caderno do curso, visitamos a seção dos objetivos, observamos a proposta de currículo integrado do curso, os processos pedagógicos e destacamos nas leituras: abordagem construtivista; aprendizagem significativa; aprendizagem baseada em problemas; dialogia e metodologias ativas. Os métodos de ensino aprendizagem estariam alicerçados em: espiral construtivista, aprendizagem baseadas em equipes e metodologia problematizadora. Algumas palavras já eram conhecidas e outras novas, contudo, era o momento de ampliar horizontes, imergir com intensidade, fazer uma ampla interlocução com os termos citados, isso foi encantador e estimulante.

A seguir faremos uma síntese refletindo sobre os movimentos realizados a partir da imersão no curso envolvendo as suas diversas fases do processo de ensino aprendizagem como: atividades de grupos, visitas continuas a plataforma moodle de ensino e construção do projeto aplicativo. Todos estes movimentos eram subsidiados pelas 
evidências. As concepções manifestadas convergem para sinalizar os alcances e mudanças ocorridos na prática profissional tendo em vista as competências geradas.

\section{O Espiral Construtivista - EC}

É uma metodologia problematizadora, idealizada a partir de experiências que desenvolvidas pelo especializando, enquanto currículo de formação adota as metodologias ativas. A primeira formulação desse método de ensino foi intuitiva e originada num desconhecimento total sobre este espiral construtivista, nunca visto antes na nossa trajetória de aprendizagem. A primeira vista a imagem do espiral trouxenos a sensação de movimentos que ocorrem com base numa visão de partes para, posteriormente, se organizar num todo.

Foi o primeiro contato em conhecer e trabalhar com EC, por meio da elaboração de narrativas. As narrativas nos trouxeram as interpretações sobre diversas questões/problemas e conflitos, aproximando-nos do processo de aprendizagem e respeitando nosso estilo e modo de ver as coisas. $O$ uso de narrativas sobre a prática simulada e produções dos especializandos, como: conquistas e desafios em relação ao curso, experiência/conflito da decisão em saúde e vivências de um enfermeiro todas foram executadas como atividades disparadoras.

Sobre a movimentação do espiral construtivista, a identificação de problemas, formulação de explicações e elaboração de questões de aprendizagem foram contempladas na síntese provisória. A busca por novas informações, a construção de novos significados e a avaliação constituíram uma nova síntese. Outro movimento importante dentro do EC foi a viagem que se fazia nas produções das novas sínteses através da busca em bases de dados e plataforma na identificação das melhores evidências para a seleção das opções para implementação das recomendações. Este momento contemplava ao mesmo tempo as opções e eram espaços para o desenvolvimento da competência, análise do contexto na gestão das políticas públicas de saúde e a tomada de decisão em saúde utilizando evidências científicas, tendo como identificação de necessidades de aprendizagem no uso das evidencias científicas.

Tendo em vista os postulados teóricos da dialética e epistemologia relata que, a síntese provisória compreende ao momento de diálogo entre os iguais e diferentes, como uma visão geral e primária da realidade, e a nova síntese, a etapa de avaliação e síntese (LIBÂNEO, 2009). A pesquisa em bases de dados e/ou repositórios, a nova síntese, constitui a viabilidade de reelaboração dos saberes, à luz das evidências. Das seis fases do ciclo da EC, apenas a busca é realizada de forma não coletiva. As fases ocorrem pela interlocução em contatos de pequenos grupos de oito a dez especializandos e um facilitador que pôde promover um conjunto de acordos para o trabalho grupal.

Na nossa experiência a produção da síntese provisória, iniciava na interatividade dos educandos com o facilitador por meio de uma questão que era o ponto de partida. As questões disparadoras eram: (i) situações-problema elaborados do cotidiano de trabalho, (ii) estudos de caso, e (iii) percepções dos especializando a partir contextos reais ou imaginários. Essa pluralidade de situações nos desencadeou a compreensão da relevância das metodologias ativas no processo pedagógico a partir de diferentes situações. Estas atividades nos permitia o encontro com: (i) situações bem elaboradas e sob condição de controle, como as questõesproblema; (ii) realidades quase estruturadas, como simulações; e (iii) condições pouco controladas, como as narrativas reflexivas ou produção elaborados a partir de casos em cenários reais.

Ao utilizar o EC, a determinação de problemas fica ligada diretamente aos saberes prévios, interpretações, sensibilidade e valores trazidos de cada aluno. Os problemas ou barreiras a se romperem e estabelecidos podem ser agregados, por aproximação, e apresentam o ponto de partida do processo pedagógico (LIMA, 2017). Deste modo, não se trata de um problema a ser estabelecido pelos alunos do grupo, mas de uns conglomerados de problemas, consequente de alcances de várias projeções e compreensões.

Por meio dos problemas pré-estabelecidos, era demonstrado no grupo os conhecimentos prévios de cada um sobre a existência de problemas que objetivava em nós o compartilhamento de explicações que comprovassem os fenômenos que observamos. Essas provocações geradas a partir da figura do facilitador promoviam no grupo a criação das hipóteses que eram anotadas no quadro para visualização das mesmas e, participação de todos na roda de discussão. A elaboração de hipóteses a serem explicadas promovia em nós tanto a elaboração de raciocínios como a produção de emoções associadas aos problemas demonstrados. Quanto mais abrangente era o quantitativo de hipóteses, observamos que melhor era o potencial para o debate e as explicações amplas realizadas. A partir daí resgatávamos os saberes prévios. Nesta etapa do ciclo elaborando hipóteses, as proposições elaboradas nas experiências/vivência de cada aluno eram respeitadas pelos facilitadores. O reconhecimento de distorções, lacunas, incoerências, ambivalências e outras provocações levavam a produção de questões de aprendizagem por meio da nova síntese.

No retorno ao novo encontro ocorria uma tempestade de ideias por meios das pesquisas realizadas nos repositórios que eram demonstrados nas rodas de discussão e debates. Nesta etapa final para conclusão do espiral construtivista tinha 
papel essencial e imprescindível o facilitador, uma vez que tinha como finalidade ampliar o nosso nível de conhecimento e compreensão sobre o problema, no grupo nas apresentações de cada especializando percebíamos as opções para implementação do problema na prática.

Os retornos eram momentos agradáveis de diálogos de compartilhamentos de nossas produções. Era encantador ver cada colega apresentando as opções encontradas sobre cada questão, como havia uma variedade de opções. Por essas características, o espiral construtivista contemplou a avaliação formativa promovendo em nós, a aprendizagem por engajamentos nas atividades. Este movimento preencheu lacunas, esclareceu dúvidas, causou conviç̧ão baseadas em evidências científicas. Com isso percebemos a maneira de construção deste processo e, também como devemos proceder no dia a dia para implementar a tomada de decisão e produto efetivos.

A avaliação deve ser verbal e realizada ao final de cada encontro. Todos os educandos devem realizar a avaliação, começando pela autoavaliação, incluindo a metacognição. O entendimento sobre os rumos cíclicos do espiral construtivista e a localização problematizadora dos especializando no curso favoreceu um estado de cientificidade, a imaginação e a criação. A mobilidade do centro do processo do educador e dos conteúdos para os participantes contemplou à proposta educacional (ROSÁRIO, 2018).

As etapas do EC são cíclicas e seus arcos são fechados nestes movimentos de elaboração da síntese provisória, nova síntese e avaliação da nova síntese em diálogo e roda de discussão. Esses momentos eram bem claros mais a compreensão que estas etapas completavam o espiral construtivista não ficava naquele momento muito claras, ou não dava sentido. Somente conseguimos esta compreensão através de leituras nos momentos de elaboração do trabalho de conclusão de curso e durante a leitura ampliada de Lima (2017), provocando algo bastante prazeroso para a compreensão e conhecimento sobre a EC.

\section{Metodologia Problematizadora - MP}

Ao longo da história e ainda hoje, o ensino tem se resumido em muitos locais e momentos como uma prática em que o educador lança conteúdos, com curto momento de debates/discussões, na maioria das vezes são provocadas atividades/exercícios nas quais as respostas produzidas demostram apenas a capacidade de memorização. Contudo, estratégias e metodológicas pedagógicas vêm sendo construídas no sentido de fazer mudanças na perspectiva da aprendizagem significativa.

A MP foi implantada como uma dessas estratégias inovadoras em que os educandos movimentam-se com a finalidade de identificar e solucionar problemas reais a partir de um contexto. Constitui-se, no entanto, uma ferramenta de aprendizagem focada no aluno, onde o mesmo deixa de ser um agente passivo neste processo e, assume um papel de protagonista de sua própria aprendizagem por meio das intervenções elaboradas produzindo melhorias nesta realidade (SOUZA; DOURADO, 2017).

Os alunos, para intervir no problema selecionado, recorrem aos conhecimentos já adquiridos, debatem, estudam, pesquisam, apreendem e integram os novos saberes. Essa integração, ensino-prática, promove a aprendizagem facilitada. Valoriza, além dos conteúdos, a forma como tudo isso vai ocorrer, oferecendo muitas vantagens, como a promoção da autonomia, a integração de conteúdo, a relação entre teoria e prática, a produção do raciocínio crítico e reflexivo, o desenvolvimento de habilidades de comunicação, e a educação autodirigida (BORGES; CHACÁ, 2014).

O infógravo apresentado no caderno do curso apresenta as etapas do arco da MP a partir da observação da realidade por um conjunto de atores identificando pontos chave e seguido de um aprofundamento teórico no sentido da construção de hipóteses para a produção de intervenções e transformação da realidade (LIMA, 2017).

No curso de especialização em GPPIE foram feitos ajustes na metodologia problematizadora inserindo o facilitador como uma figura importante neste processo no sentido de ampliar a autonomia do especializando. Esta metodologia irá contemplar a sistematização para a elaboração/produção do projeto aplicativo (SILVA, 2017).

Segundo o autor citado anteriormente, o projeto aplicativo (PA) é uma produção do tipo pesquisa-ação. Essa interação entre a teoria à prática tornou-se um importante eixo educacional em metodologias ativas do ensinoaprendizagem, pois busca associar conhecimento e ação para dar respostas técnicas e políticas que visem melhores práticas.

No início do curso fizemos uma reflexão sobre as metodologias ativas através da construção de um painel focalizando perguntas provocadas pelos facilitadores relacionadas à questão da nova metodologia proposta. $\mathrm{Na}$ vida acadêmica e profissional já simpatizávamos e seguíamos as metodologias ativas. Assim, este momento era visto por todos como uma etapa de ampliação da percepção e prática. Fomos instigados a produzir uma síntese provisória e uma nova síntese relacionadas as metodologias ativas, conquistas e desafios em relação ao curso.

Assim sendo, nossa visão foi fortemente iniciada ao longo dos encontros, quando da participação em um Team-Based Learning ( $\mathrm{TBL}$ ), aprendizagem baseada em equipes, uma 
forma de aprendizagem colaborativa promovido pelo curso, onde foi discutido a temática projeto aplicativo no contexto das inciativas educacionais. A leitura do caderno do projeto aplicativo como atividade prévia do TBL nos deixou confusos, pois a compreensão de sua elaboração por ser minuciosa e cheia de produção de árvores explicativas e planilhas nos parecera redundantes.

Nas primeiras imersões na construção do projeto aplicativo foi realizada a primeira oficina de trabalho de projeto aplicativo através de atividade em grupo, onde foi exibido um vídeo demonstrando um encontro entre diversos profissionais que tem a função em gestão de serviços de saúde na cidade de Tégea (grande Polis), onde estes elaboraram as fragilidades das Redes de atenção à saúde desta cidade fictícia. Esta exibição nos proporcionou um entendimento melhor para a realização do projeto.

Logo após a atividade apresentada dos vídeos circulando saberes, cada membro do grupo indicou em targetas três problemas na rede local. Os grupos apresentaram suas respectivas árvores construídas organizando por núcleos de sentidos e identificando macroproblemas e identificando soluções. No final da oficina cada grupo elaborou o seu tema do projeto aplicativo a partir das provocações sentidas.

Essas ações executadas anteriormente ampliaram a compreensão, antes limita unicamente a identificar problemas e a propor soluções de forma fragmentadas e sem as contextualizações. A metodologia utilizada na construção do PA proposta pelo curso como estratégia de aprendizagem favorecia a elaboração e planejamento detalhado, o que enriquecia o processo. Isso ficou bem claro para todos.

\section{Aprendizagem Baseada em Equipes - TBL}

A princípio apenas uma sigla nova que significava: team based learn (aprendizagem baseada em time). Até então nunca havíamos ouvido falar ou participado desta estratégia de ensino, mas de início, já percebíamos que era inovadora. A sensação preliminar era coisa das metodologias ativas e, isto é empolgante. O primeiro TBL foi laboratório para todos, precisávamos ver como aquela ideia se formatava. Percebido que nesta, o forte não era a mera transmissão de conteúdo, mas uma estratégia pedagógica. A TBL era construída em vários movimentos e por diferentes autores, todos protagonistas (especializandos, facilitadores, convidados e o moderador), estes atores atuando ao mesmo tempo e em conjunto formavam o time a caminho de promover o ensino. A aprendizagem era fortemente trabalhada e garantida pelos movimentos, de inundação nos conteúdos e questões reflexivas trabalhadas e, que o tempo todo fazia os especializando estarem atentos.

Antes dos atores convidados entrarem em ação, existia o movimento prévio de contato dos especializandos com o tema objeto da ação da TBL, neste momento em grupo imergíamos em leitura de termos de referência. No segundo momento fazíamos leituras individuais de questões objetivas disparadas na busca de suas respostas. $O$ terceiro movimento ocorreria em encontros de grupos e ou em duplas onde debatíamos e conciliávamos respostas que expressassem a coesão do grupo a partir de novas reflexões, contraposições e negociações.

Contudo, em um quarto movimento, ouvíamos os convidados exporem de forma alternada cada questão em detalhes e nuanças. Todas as respostas tinham "recheio" de certeza. Assim até o final da exposição geravam uma expectativa em nós sobre qual resposta estava mais correta. O moderador também contribuía com ponderações. A TBL ocorria, algumas vezes, em movimentos intercalados de ida e volta em teleconferência entre, responder as cinco questões e as respectivas correções.

Outro ponto importante no curso que merece destaque foi a formação de grupos e equipes na busca da aprendizagem por significância ao qual promovia a dialogicidade entre os especializandos e os facilitadores. Boa parte das atividades era realizada de forma coletiva no sentido de trocas de experiências e apoio mútuo na elaboração e reelaboração de novos saberes. Esses movimentos contínuos permitiam o tempo todo estarmos aprendendo com os outros através de exercícios, trabalhos de grupos, oficinas, avaliações. Tudo isso integrando valores de solidariedade e corresponsabilização.

\section{Ações Educacionais Diversificadas - AED}

As atividades sempre eram programadas e organizadas em grupos diversidade, equipe diversidade e/ou grupos afinidades com várias formações ao longo do curso, o que enriquecia o processo. Ficamos bastante surpreendidos com estas formações, pois eram dinâmicas e preveniam a ociosidade e a mesmice. Estes grupos se encontravam em momento de atividades autodirigidas, discussões, rodas de conversações, viagens emocionais, compartilhamentos de narrativas, sínteses provisórias e nova síntese, oficinas de trabalhos, TBLs, produção de etapas do projeto aplicativo, análises de situações problemas, produção de painéis, exibição de vídeos educativos, e avaliações formativa e somativas.

As AED's foram marcantes no curso com forte impacto na formação das competências: construção do portifólio pela complexidade e integração ensino serviço e teoria e prática. $O$ caderno PA inédito com estratégias próprias e com a confecção de planilhas e /ou árvores explicativas foram inovadores, juntamente com os vídeos e os painéis complementavam a metodologia de compreensão das 
mesmas. Destacou-se ainda a produção do portfólio construtivista que tinha a finalidades de demonstrar todo este processo de aprendizagem e miscelânea como um diário de bordo com todas as nossas subjetividades, retratando-se como uma produção reflexiva, subjetiva e carregada de percepções, ganhos, produção e evolução. Mesmo sendo individual a sua produção, fomentava a troca de informações entre os facilitadores e colegas de turma sobre esta construção. Cada aluno fazia do seu portfólio a sua cara pela demonstração de riquezas de detalhes.

Os momentos individuais ocorriam basicamente em estudos autodirigidos para cumprimentos dos pactos $E A D$, pesquisas, leituras, elaboração de atividades, acesso a plataforma moodle do curso, leitura de livros e materiais didáticos. Mesmos em atividades individuais, os especializandos sentiam-me motivados, pois, esta ação indiretamente promovia trocas de informações entre participantes do curso em momentos de aprendizagem.

Diversas ações educacionais estruturantes na perspectiva de complementar uma aprendizagem construtivista auxiliaram no nosso processo de formação do especializando visando o alcance das competências do curso e o perfil do egresso a ser formado. Tudo isso aliado à intencionalidade das necessidades de aprendizagens dos especializandos, a realidade de trabalho no qual o mesmo estava inserido e a visão de integração da teoria e prática para o fortalecimento do processo de ensino aprendizagem através das metodologias ativas:

A vivência com toda esta gama de estratégias de ensino nos permitiu refletir e a valorizar pedagogicamente mais a metodologia do que o ensino e, isso foi transformador em nossas práticas de trabalho. Passamos a fortalecer as metodologias ativas na vida cotidiana. Isto trouxe mais impactos positivos no nosso processo de trabalho em equipe, pois aprendemos coisas novas. As viagens emocionais foram enriquecedoras e trabalharam a abordagem centrada na pessoa, focando os valores, princípios éticos e sentimentalidade.

\section{CONCLUSÃO}

A participação do processo de formação em educação permanente no curso de especialização em gestão de políticas públicas informadas por evidências foi uma vivência altamente satisfatória principalmente, por realizarmos esse trajeto, ancorados pelas metodologias ativas, o que tornou esta viagem mais agradável e sem turbulências.

Um número consideráveis de professores têm uma percepção de modelo educacional dialógico e que promova a autonomia dos educandos isto é fato. Contudo a maioria dos professores utiliza uma prática bancária de educação conforme pressupostos freiriano. Assim necessitamos ampliar uma visão questionadora que promova discussões, argumentação para um posicionamento fundamentado do aluno por meio e uma construção coletiva. Participar desta experiência no fez perceber que o mais relevante não são as metodologias ativas, mas sim uma aprendizagem ativa que promova alunos engajados e participativos e, isso não se constrói com meros professores expositores de conteúdos. Estamos na era da comunicação e as informações estão presentes em todos os lugares onde o nosso aluno não tem dificuldade de acessar o Google a qualquer momento.

Devemos focar nossos esforços de aprendizagem partindo de objetivos elaborados pelos alunos, no que ele sente, na sua emoção e no que lhe toca, pois o conhecimento bom não é transmitido é construído. Enquanto educando ativos no processo as experiências do curso nos trouxeram reflexões que foram verdadeiras contribuições para desenvolver uma pedagogia moderna trazendo a ruptura com paradigmas e provocando inquietações que oportunizarão, crescimento, dinamismo na nossa vida docente daqui para frente.

\section{REFERÊNCIAS}

BORGES, M.C.; CHACÁ, S.G.F.; QUINTANA, S.M.; FREITAS, L.C.; RODRIGUES, M.L.V. Aprendizado baseado em aprendizado baseado em problemas. Medicina (Ribeirão Preto), v.47, n.3, p.301-7, $2014 . \quad$ Disponível em: http://revista.fmrp.usp.br/2014/vol47n3/8_Aprendizadobaseado-em-problemas.pdf. Acesso em: 12 dez. 2019.

BRASIL. Ministério da Saúde. Secretaria de Ciência, Tecnologia e Insumos Estratégicos. Departamento de Ciência e Tecnologia. Síntese de Evidências para Políticas de Saúde: estimulando o uso de evidências científicas na tomada de decisão/Ministério da Saúde, Secretaria de Ciência, Tecnologia e Insumos Estratégicos, Departamento de Ciência e Tecnologia. - 2. ed. - Brasília: Ministério da Saúde, 2016. Disponível em:

http://bvsms.saude.gov.br/bvs/publicacoes/sintese_evidenci as_politicas_saude_1ed.pdf. Acesso em: $12 \mathrm{dez} .2019$.

BRASIL, Ministério da Saúde. Conselho Nacional de Saúde. Resolução CNS № 466, DE 12 DE dezembro de 2012. Disponível em: < https://conselho.saude.gov.br/resolucoes/2012/Reso466 .pdf>. Acesso em: 12 dez. 2019

CAREgNATO, R. C. A; MUTTI, R. Pesquisa qualitativa: análise de discurso versus análise de conteúdo. Texto \& Contexto Enfermagem, v.15, n.4, p.679-684, 2006. Disponível em: http://dx.doi.org/10.1590/S0104-07072006000400017. Acesso em: 12 dez. 2019. 
CHIARELLA, T.; BIVANCO-LIMA, D.; MOURA, J.C.; MARQUES, M.C.C.; MARSIGLIA, R.M.G. A Pedagogia de Paulo Freire e o Processo Ensino Aprendizagem na Educação Médica. Revista brasileira de educação médica, v.39, n.3, p.418425, 2015. Disponível em: https://doi.org/10.1590/198152712015v39n3e02062014. Acesso em: 12 dez. 2019.

SILVA, S. F da. Especialização em Gestão de Políticas Públicas de Saúde Informadas por Evidências. CADERNO do curso 2015/2016. São Paulo: Instituto Sírio-Libanês de Ensino e Pesquisa; Ministério da Saúde, 2015. 50p. Disponível em: https://iep.hospitalsiriolibanes.org.br/documents/66515 /69212/Caderno+Espie+-+Portugu\%C3\%AAs/6a141362dad4-4398-b1ac-8fd2053c63c4 . Acesso 14 dez. 2019.

SILVA, S. F da. Especialização em Gestão de Políticas de Saúde Informadas por Evidências. Instituto Sírio Libanês de Pesquisa e Ensino, São Paulo: Ministério da Saúde, 2017. Disponível em: https://www.hospitalsiriolibanes.org.br/responsabilidade -social/projetos-de-apoio-ao-sus/projetos/ensinocapacitacao-recursos-humanos/Paginas/especializacaogestao-politicas-saude-informadas-evidencias.aspx. Acesso 14 dez. 2019.

DELUIZ, N. O Modelo das Competências Profissionais no Mundo do Trabalho e na Educação: Implicações para o Currículo. Boletim Técnico Senac. 2001; v.27, n.43. Disponível em: http://www.bahiana.edu.br/CMS/Uploads/O\%20modelo \%20das\%20competencias\%20profissionais\%20N_Deluiz. pdf. Acesso em: 14 dez. 2019.

EPSTEIN, R.M.; HUNDERT, E. M. Defining and Assessing Professional Competence. JAMA, v.287, p. 226-35, 2002. Disponível

em: http://quarto_ano_2008_2.pdf.medicina.ufg.br/up/148/ o/Defining_and_Assessing.pdf Acesso em: 08 abr. 2018.

FOFONCA, E.; ESTEVAM, M.; COSTA, K.A.S et al. Metodologias pedagógicas inovadoras: contextos da educação básica e da educação superior. Curitiba: Editora IFPR, 2018. 183p. Disponível em: < https://reitoria.ifpr.edu.br/wpcontent/uploads/2018/08/E-book-MetodologiasPedag\%C3\%B3gicas-Inovadoras-V.1_Editora-IFPR2018.pdf>. Acesso em: 8 abr. 2018.

FREITAS, A.P de. Zona de desenvolvimento proximal: a problematização do conceito através de um estudo de caso. Tese de Doutorado. Unicamp. São Paulo, 2001. Disponivel em: http://taurus.unicamp.br/bitstream/REPOSIP/251042/1/ Freitas_AnaPaulade_D.pdf > Acesso em: 08 abr. 2018.

LIBÂNEO, J. C. Democratização da escola pública: a pedagogia crítico-social dos conteúdos. São Paulo: Loyola; 2009.

MOZZATO, A.R. Análise de Conteúdo como Técnica de Análise de Dados Qualitativos no Campo da Administração:
Potencial e Desafios. Revista de Administração Contemporânea, v. 15, n. 4, p. 731-747, 2011. Disponível em:

http://www.scielo.br/pdf/rac/v15n4/a10v15n4.pdf>. Acesso em: 08 abr. 2018.

LIMA, V. V. Espiral Construtivista: uma metodologia ativa de ensino-aprendizagem. Interface (Botucatu), v.21, n.61, p.421-34, 2017. Doi: http://dx.doi.org/10.1590/180757622016.0316. Acesso em 15 dez. 2019.

ROSÁRIO, A.C.M.B.A. Sistema de avaliação cognitiva: contributos para a sua validação em alunos do ensino básico do concelho de Évora. Tese apresentada à Universidade de Évora para obtenção do Grau de Doutor em Psicologia Especialidade: Psicologia da Educação. Universidade de Évora. Évora. 2014. Disponível em: https://dspace.uevora.pt/rdpc/bitstream/10174/13033/1 /tese-ana-cristina-rosario.pdf . Acesso em 14 dez. 2019.

SOUZA, S.C.; DOURADO, L. Aprendizagem Baseada em Problemas ( $A B P$ ): Um método de aprendizagem inovador para o ensino educativo. Holos, v.31, n.5, 182-200, 2015. Disponível em: http://www2.ifrn.edu.br/ojs/index.php/HOLOS/article/vi ewFile/2880/1143. Acesso em: 15 dez. 2019.

THOFEHRN, M. B.; LEOPARDI, M. T. Construtivismo sóciohistórico de Vygostky e a Enfermagem. Revista Brasileira de Enfermagem, v.59, n.5, p.694-98, 2006. Doi: http://dx.doi.org/10.1590/S0034-71672006000500019. Acesso 18 abr. 2018.

Submissão: 06/05/2020

Aprovado para publicação: 14/05/2020 